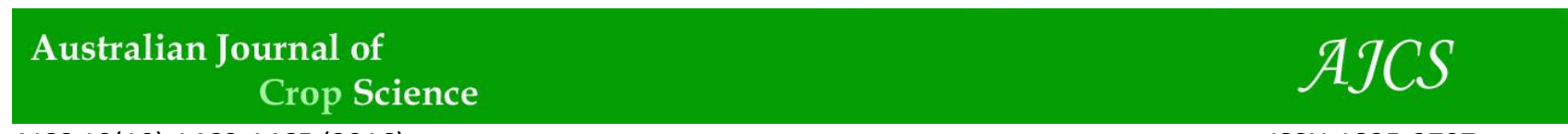

AJCS 10(10):1460-1465 (2016)

ISSN:1835-2707

DOI: 10.21475/ajcs.2016.10.10.p7750

\title{
Exploiting cucurbitaceous species as rootstocks for management of Fusarium wilt (Fusarium oxysporum) in bitter gourd
}

\author{
N. A. Tamilselvi ${ }^{*}$, L. Pugalendhi ${ }^{2}$ and T. Raguchander ${ }^{3}$ \\ ${ }^{1}$ Department of Vegetable Crops, Horticulture College and Research Institute, Tamil Nadu Agricultural \\ University, Coimbatore-641 003, India \\ ${ }^{2}$ Tapioca and Castor Research Station, Yethapur, Salem-636 119, India \\ ${ }^{3}$ Agricultural College and Research Institute, Vazhavachanur, Thiruvannamalai, India
}

*Corresponding author: tamilaaru@gmail.com

\begin{abstract}
Bitter gourd is affected by various kinds of pathogens, of which Fusarium wilt Fusarium oxysporum plays a vital role. The present investigation focuses on the role of defense related enzymes which impart resistance against Fusarium wilt. A total of ten cucurbitaceous rootstocks and two bitter gourd scions were screened against Fusarium wilt pathogen under in vitro. Results on screening against Fusarium wilt revealed that Citrullus colocynthis, Cucumis metuliferus and Cucurbita moschata exhibited no symptom and manifested as resistant to Fusarium wilt and the least percent incidence of 21.62, 37.44 and 48.90 was observed in Luffa cylindrica followed by Momordica charantia var. muricata rootstock (23.58, 42.18 and 50.34) at 30, 45 and 60 days after inoculation. Seedlings of aforementioned species were harvested at $0,7,14,21,28$ and 35 days after challenge inoculation and assayed for defense related enzymes activity. Significant increases in the activities of peroxidase (PO), polyphenol oxidase (PPO) and phenylalanine ammonia lyase (PAL) activity was observed in resistant rootstocks viz., C. colocynthis, C. metuliferus and C.moschata followed by moderately resistant rootstocks viz., M. charantia var. muricata and L. cylindrica. Native page analysis of both PO and PPO isozymes was carried out for the time course and examined. Isozyme analysis revealed that unique PO and PPO isozymes were induced in aforementioned resistant rootstocks. From this study point out that the cucurbitaceous species viz., kumatikai (C. colocynthis), African horned cucumber (C. metuliferus) and pumpkin (C. moschata) with high or moderate levels of these biochemical constituents suffered less for Fusarium wilt pathogen and these rootstocks served as the best rootstocks for grafting with bitter gourd scions followed by mithipakal(M. charantia var. muricata) and sponge gourd (L. cylindrica).
\end{abstract}

Keywords: Fusarium wilt, grafting, cucurbitaceous rootstocks, bitter gourd.

Introduction

Bitter gourd (Momordica charantia L.) is one of the important cucurbitaceous vegetable grown in India. Among the cucurbits, it is considered a prized vegetable because of its high nutritive value especially ascorbic acid and iron (Behera, 2004). Depending on location, bitter gourd is also known as bitter melon, Karela or Balsam pear. The immature fruits and tender vine tips are used in a variety of culinary preparations. It is a most common vegetable cultivated throughout India during warm season (Satkar et al., 2013). Bitter gourd has been used in various herbal medicine systems for a long time because of its disease preventing and health promoting phytochemical compounds like dietary fiber, minerals, vitamins, flavonoids and antioxidants. It is also used for reduction of blood sugar levels in the treatment of type-2 diabete (Singh et al., 2013).

The crop is cultivated over an area of 80990 ha in India with an annual production of $8,30,450$ tonnes and the productivity of 10.25 tha $^{-1}$ (www.indiastat.com, 2015-16). The main problem with bitter gourd production in India is Fusarium wilt and root knot nematode. (Tamilselvi, 2014). Fusarium wilt is caused by Fusarium oxysporum is responsible for a wider range of diseases on economically important crops including bitter gourd, watermelon and cucumber. It is the most devastating soil borne disease and one of the major yield limiting constraint which cause profound economic losses ranging from 30 to 50 per cent under dry warm conditions (Tamilselvi and Pugalendhi, 2015). Fusarium wilt symptoms include damping-off, seedling disease or wilt during any stage of plant development. Symptoms on mature plants typically appear following fruit set and may appear as a dull grey green appearance of the leaves followed by yellowing of the crown foliage, wilting during the day and eventual death. Brown stripes will develop on stems and branches of infected plants. Vascular discoloration is visible inside stem and stem collars often turn dark brown. There are different ways to circumvent these soil diseases such as culturally by crop rotation, biological control, soil fumigation by the use of chemicals and development of resistant varieties through breeding programs. The management practices have some disadvantages. Hence, the selection of resistant rootstocks to soil borne pathogens seems to be an effective solution

Aside from the initial reports, little information on the pathogenicity of $F$. oxysporum is available. This knowledge would be important for identification of resistant rootstocks against soil borne diseases. This is particularly important as 
cucurbitaceous species were often used as rootstocks for grafting in bitter gourd, cucumber and watermelon to control Fusarium wilt and other soil borne diseases. In view of this fact, the cucurbitaceous rootstocks and bitter gourd scions were screened against Fusarium wilt pathogen under pot culture to identify the resistant species for further studies.

The defense enzymes viz., Peroxidase (PO), Polyphenol oxidase (PPO) usually accumulates upon wounding in plants which catalyze the formation of lignin and other oxidative phenols. Phenylalanine ammonia lyase is the key enzyme in inducing synthesis of salicylic acid (SA), phytoalexins and phenolics which induces systemic resistance in many plants. However, screening of cucurbitaceous rootstocks against Fusarium wilt and observation on involvement of defense related enzymes were limited. Hence, the present study aimed to evaluate the involvement of defense enzymes such as peroxidase(PO),Polyphenol oxidase (PPO) and Phenylalanine ammonia lyase (PAL) in cucurbitaceous rootstocks and bitter gourd scions after challenge inoculation with Fusarium oxysporum.

\section{Results}

\section{Response of cucurbitaceous rootstocks and bitter gourd} scions against Fusarium wilt incidence

A pot culture experiment was conducted to study the response of cucurbitaceous rootstocks and bitter gourd scions to Fusarium wilt. Findings of this study indicated that, kumatikai ( $C$. colocynthis), African horned cucumber (C. metuliferus) and pumpkin (C. moschata) exhibited no symptom and manifested as resistant to Fusarium wilt and sponge gourd (L. cylindrica) and mithipakal (M. charantia var. muricata) showed moderately resistant reaction under in vitro (Table 1$)$.

\section{Biochemical basis of defence response in cucurbitaceous rootstocks and bitter gourd scions}

In addition, biochemical defense mechanism against Fusarium wilt in cucurbitaceous rootstocks and bitter gourd scions were studied. The PO activity was assayed in aforementioned species from $0,7,14,21,28$ and 35 days after challenge inoculation. The PO activity was induced after inoculation and increased activity was observed from seventh day to $21^{\text {st }}$ day after inoculation and thereafter gradual decrease in activity was recorded. The highest activity of PO was observed in kumatikai (C. colocynthis) (3.82 changes in OD $\min ^{-1} \mathrm{~g}^{-1}$ of root) followed by African horned cucumber $(C$. metuliferus) (3.25 changes in OD $\mathrm{min}^{-1} \mathrm{~g}^{-1}$ of root) and pumpkin (C. moschata) (2.90 changes in OD $\mathrm{min}^{-1} \mathrm{~g}^{-1}$ of root) (Fig 1). The two bitter gourd scions (Palee $F_{1}$ and $C O$ 1) showed a slow increase in PO activity from seven days after inoculation and showed a declining trend at 35 days after inoculation.

PPO activity was also measured in the roots of Fusarium wilt pathogen inoculated cucurbitaceous rootstocks and bitter gourd scions. The plants showed increased level of polyphenol oxidase activity and reached the highest level on $21^{\text {st }}$ day after inoculation thereafter declined. The highest PPO activity was recorded in kumatikai (C. colocynthis) (3.23 changes in OD $\mathrm{min}^{-1} \mathrm{~g}^{-1}$ of root) followed by African horned cucumber (C. metuliferus) (3.14 changes in OD $\mathrm{min}^{-}$ ${ }^{1} \mathrm{~g}^{-1}$ of root) and pumpkin (C. moschata) (3.08 changes in OD $\min ^{-1} \mathrm{~g}^{-1}$ of root) (Fig 2).

The cucurbitaceous rootstocks and bitter gourd scions were also analyzed for phenylalanine ammonia lyase (PAL) activity after inoculation with Fusarium wilt pathogen. The results revealed that the plants induced to synthesize higher level of PAL enzyme activity. The activity of enzyme reached the highest level on 21 days after challenge inoculation and thereafter declined with decreasing rate. The highest PAL activity among the rootstocks was noticed in kumatikai (C. colocynthis) (31.59 nmol of trans cinnmic acid $\min ^{-1} \mathrm{~g}^{-1}$ of root) followed by African horned cucumber $(C$. metuliferus) (31.20 nmol of trans cinnmic acid $\mathrm{min}^{-1} \mathrm{~g}^{-1}$ of root) and pumpkin (C. moschata) $(29.71 \mathrm{nmol}$ of trans cinnmic acid $\min ^{-1} \mathrm{~g}^{-1}$ of root) (Fig 3).

Native gel electrophoresis was done to study the isozyme variation among the cucurbitaceous rootstocks and bitter gourd scions. The roots of the aforementioned species were taken at 21 days after inoculation.

The results of the PO isozyme analysis revealed that, number and intensity of isoforms was varying among the species.

More number of isoforms (PO1, PO2, PO3 and PO 4) was observed in the resistant rootstocks viz., Kumatikai (C. colocynthis), African horned cucumber (C. metuliferus) and pumpkin (C. moschata) followed by moderately resistant rootstocks viz., Mithipakal (M. charantia var. muricata) and sponge gourd (L. cylindrica) compared to susceptible rootstocks and bitter gourd scions (Supplementary Figure 1). Native gel electrophoretic separation of enzyme extract from the cucurbitaceous rootstocks and bitter gourd scions showed PPO isoforms. Among the cucurbitaceous rootstocks and bitter gourd scions, the rootstocks viz., Kumatikai (C. colocynthis), African horned cucumber (C. metuliferus) and pumpkin (C. moschata) found to be resistant. At 21 days after challenge inoculation with Fusarium wilt pathogen showed more number of isoforms but the other species showed only less isoforms with less intensity (Supplementary Figure 2).

\section{Discussion}

Findings of this study indicated that, kumatikai (C. colocynthis), African horned cucumber (C. metuliferus) and pumpkin (C. moschata) exhibited no symptom and manifested as resistant to Fusarium wilt followed by sponge gourd (L. cylindrica) and mithipakal (M. charantia var. muricata) rootstocks showed moderately resistant reaction under in vitro. There was no earlier report in India regarding resistance to Fusarium wilt and this would be the first record of evidence to show that these species are resistant to Fusarium wilt. But the available reports from foreign countries showed that muskmelon grafted onto C.metuliferus, C.maxima and C.moschata showed resistance against Fusarium wilt (Nisini et al., 2002). Mohamed et al. (2012) reported that grafting watermelon onto inter-specific hybrid 'Nun 6001' (Cucurbita maxima x Cucurbita moschata) also showed resistant reaction to this disease.

On infection with Fusarium wilt pathogen, the activity of the enzyme increased significantly in resistant species, which in turn led to formation of more quinones and other oxidation products, resulting in reduced multiplication and inactivation of the pathogen (Singh and Singh, 1989). Higher level of expression of defense-related proteins and timely accumulation of chemicals at the infection site certainly prevent the colonization of pathogen in the plant species (Saravanakumar et al., 2007).

Among the different defense gene products, peroxidases are important in conferring resistance against many pathogens. PO represents important component of an early response in plant pathogen attack and play a key role in biosynthesis of lignin which limit the extent of pathogen spread (Bruce and 
Table 1. Fusarium oxysporum incidence on cucurbitaceous rootstocks and bitter gourd scions under in vitro.

\begin{tabular}{|c|c|c|c|}
\hline \multirow{2}{*}{ Rootstocks } & \multicolumn{3}{|c|}{ Fusarium wilt incidence (\%) } \\
\hline & $30 *$ DAP & $45^{*} \mathrm{DAP}$ & $60 *$ DAP \\
\hline $\begin{array}{l}\text { Mithipakal } \\
\text { (Momordica charantia var. muricata) }\end{array}$ & $23.58(4.90) \pm 1.8$ & $42.18(6.83) \pm 3.2$ & $50.34(7.40) \pm 3.7$ \\
\hline Fig leaf gourd (Cucurbita ficifolia) & $48.21(6.97) \pm 3.7$ & $62.63(7.94) \pm 4.3$ & $78.35(8.87) \pm 5.2$ \\
\hline Pumpkin (Cucurbita moschata) & $0(0.70) \pm 0.0$ & $0(0.70) \pm 0.0$ & $0(0.70) \pm 0.0$ \\
\hline Zucchini squash (Cucurbita pepo) & $63.32(7.98) \pm 4.5$ & $78.94(8.91) \pm 5.4$ & $92.30(9.63) \pm 6.6$ \\
\hline Sponge gourd (Luffa cylindrica) & $21.62(4.70) \pm 1.5$ & $37.44(6.15) \pm 2.7$ & $48.90(7.30) \pm 3.5$ \\
\hline Ridge gourd (Luffa acutangula) & $42.44(6.55) \pm 2.9$ & $65.37(8.11) \pm 4.5$ & $80.71(9.01) \pm 5.5$. \\
\hline Bottle gourd (Lagenaria siceraria) & $46.84(6.88) \pm 3.2$ & $74.67(8.67) \pm 5.3$ & $88.41(9.42) \pm 6.3$ \\
\hline Ash gourd (Benincasa hispida) & $48.33(6.98) \pm 3.8$ & $53.62(7.35) \pm 3.4$ & $84.94(9.24) \pm 6.2$ \\
\hline Kumatikai (Citrullus colocynthis) & $0(0.70) \pm 0.0$ & $0(0.70) \pm 0.0$ & $0(0.70) \pm 0.0$ \\
\hline $\begin{array}{l}\text { African horned cucumber } \\
\text { (Cucumis metuliferus) } \\
\text { Scions }\end{array}$ & $0(0.70) \pm 0.0$ & $0(0.70) \pm 0.0$ & $0(0.70) \pm 0.0$ \\
\hline Momordica charantia cv. Palee $\mathrm{F}_{1}$ & $46.22(6.83) \pm 3.5$ & $64.66(8.07) \pm 5.7$ & $80.94(9.02) \pm 6.4$ \\
\hline Momordica charantia cv. CO 1 & $50.55(7.14) \pm 4.0$ & $78.56(8.89) \pm 5.5$ & $89.38(9.48) \pm 6.3$ \\
\hline SEd & 0.5318 & 0.6463 & 0.7088 \\
\hline $\mathrm{CD}$ at $(0.05)$ & 1.1029 & 1.3403 & 1.4699 \\
\hline
\end{tabular}

Figures in parentheses are square root $(\mathrm{X}+0.5)$ transformed values.

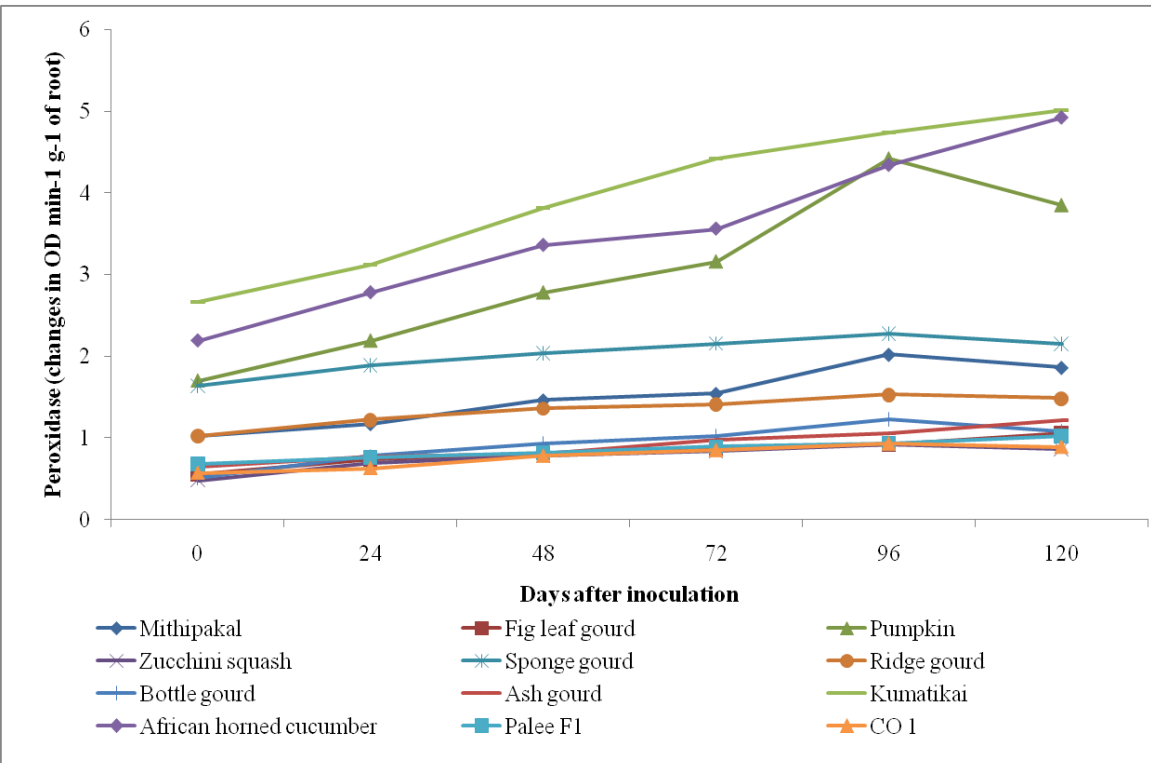

Fig 1. Induction of PO activity in cucurbitaceous rootstocks and bitter gourd scions against Fusarium oxysporum.

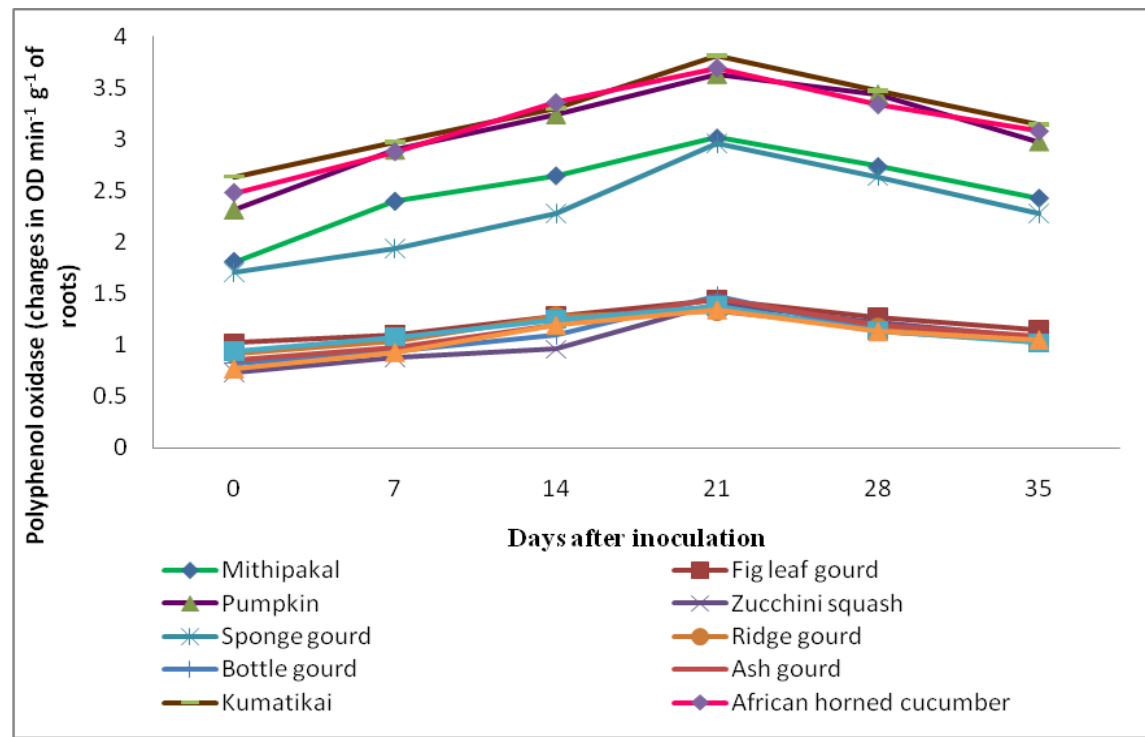

Fig 2. Induction of PPO activity in cucurbitaceous rootstocks and bitter gourd scions against Fusarium oxysporum. 


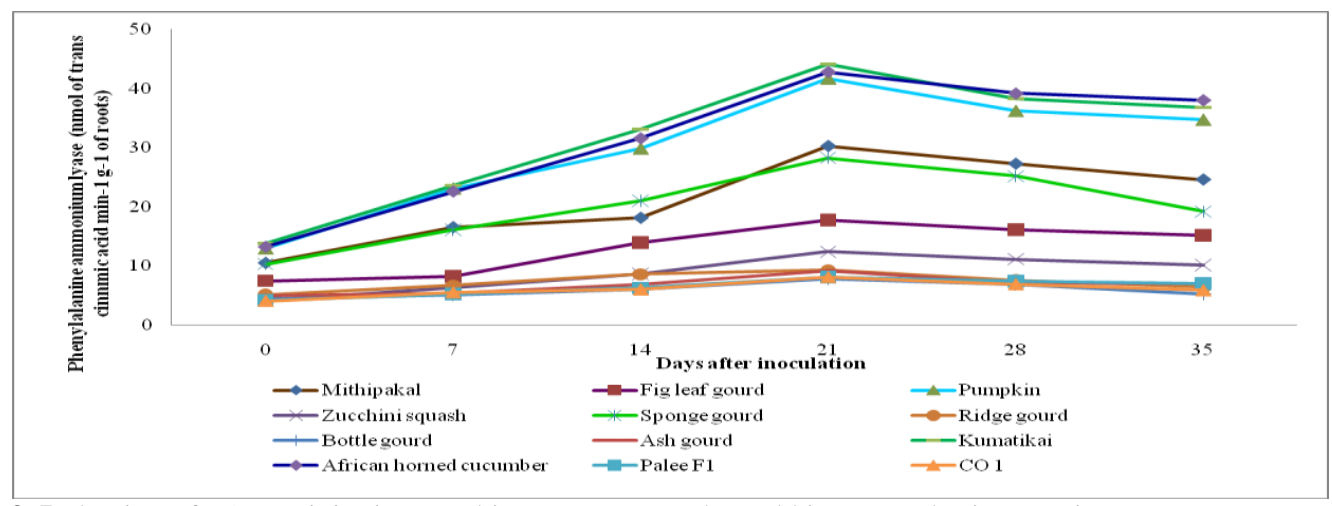

Fig 3. Induction of PAL activity in cucurbitaceous rootstocks and bitter gourd scions against Fusarium oxysporum.

West, 1989). The product of this enzyme is the presence of a hydrogen donor and hydrogen peroxidase have antimicrobial activity and even antiviral activity (Van and Callow, 1983). In this study, increased PO activity was observed in kumatikai (C. colocynthis), African horned cucumber ( $C$. metuliferus) and pumpkin (C. moschata) at different intervals after inoculation. The enzyme level was increased after pathogen reaction and reached the peak at 21 DAI, then gradually decreased. Similar such observation of increased PO activity was also reported by Kohatsu et al. (2013) when cucumber plants grafted onto 'Shelper' squash and 'Greenstripped cushaw squash against soil borne diseases.

PPO is induced via octadecanoid defense signal pathway which is usually associated with feeding by insects or similar physical trauma. It involves jasmonic acid as an intermediate signal and culminates in the production of proteins such as PPO and proteinase inhibitors (Schaller and Ryan, 1995). The PPO activity varied significantly among rootstocks and bitter gourd scions under in intro. Susceptible rootstocks and bitter gourd scions had lower polyphenol oxidase activity. Significantly elevated PPO activity was observed in resistant rootstocks viz., kumatikai (C. colocynthis), African horned cucumber (C. metuliferus) and pumpkin (C. moschata) and it catalyses the last step of biosynthesis of lignin and other oxidative phenols. As sown in Figure 2, the PPO activity increased significantly 7 days after challenge inoculation and reached the highest level at 21 days after inoculation then gradually decreased. These observations are in line with the findings of Sherly (2010) in brinjal grafted onto S. torvum rootstock challenged with dry root rot pathogen and cucumber plants grafted onto 'Shelper' squash and 'Greenstripped cushaw' squash against soil borne diseases (Kohatsu et al., 2013).

PAL is the key enzyme in inducing the synthesis of salicylic acid (SA), which is responsible for inducing systemic resistance in many plants. The time required to activate the defence mechanisms is important for suppression of the invading pathogen. The increased activity of PAL constituted for enhancing the resistance in kumatikai $(C$. colocynthis), African horned cucumber (C. metuliferus) and pumpkin (C. moschata) against fungal pathogen and these rootstocks excelled for this trait. Earlier and higher level of expression of PAL activity was observed in resistant rootstocks throughout the experimental period. The enzyme activity was remain constant in susceptible rootstocks and bitter gourd scions. Several studies have shown that induction of PAL activity in Colletotrichum capsici resistant chilli genotypes (Jabeen et al., 2009) and in Solanum torvum rootstock against dry root rot pathogen (Sherly, 2010). These results indicated that all these biochemical constituents are responsible for conferring resistance to Fusarium wilt pathogen. These findings are in line with Sherly (2010) in brinjal for $M$. incognita and dry root rot pathogen (Macrophomina phaseolina).

Findings of this study point out that the rootstocks viz., kumatikai (C. colocynthis), African horned cucumber $(C$. metuliferus) and pumpkin (C. moschata) with high or moderate levels of these biochemical constituents suffered less with Fusarium wilt disease and these rootstocks served as the best rootstocks for grafting with bitter gourd scions followed by mithipakal (M. charantia var. muricata) and sponge gourd (L. cylindrica).

Isozyme analysis by electrophoresis provides a well defined and effective method to detect genetic differences among individuals. Among the organic molecules, isozymes are very useful, which aid in comparing the genotypes, though they are used only as a supplementary tool along with morphological, genetical or other biochemical methods. In the present investigation, isozyme pattern of PO and PPO were studied in cucurbitaceous rootstocks and bitter gourd scions at 21 days after challenge inoculation with Fusarium wilt pathogen. In PO and PPO isozyme analysis more isoforms were present in resistant rootstocks viz., kumatikai (C. colocynthis), African horned cucumber (C. metuliferus) and pumpkin (C. moschata). However moderately resistant species viz., Mithipakal (M. charantia var. muricata) and sponge gourd (L. cylindrica) also have isoforms which are lesser than resistant species but higher than isoforms which present in susceptible rootstocks and bitter gourd scions.

With respect to PPO, the susceptible rootstocks and bitter gourd scions had faint bands. In resistant species there was an increase in isoform expression with improved expression of band followed by moderately resistant species. The results of the present study on isozyme profile revealed that there was an improved banding pattern with respect to the intensity of the band and also with the increase in the band number in resistant species followed by in moderately resistant species. This may be attributed to the expression of structural genes, which have expressed after challenge inoculation. This finding falls in line with Sherly (2010) in brinjal against dry root rot pathogen and Ramyabharathi (2011) and Prabhukarthikeyan (2012) against Fusarium wilt respectively.

\section{Materials and Methods}

\section{Experimental site and Plant materials}

The pot culture experiment was carried out from 2013 to 2014 at the Department of plant pathology glasshouse, Tamil Nadu Agricultural University, Coimbatore, India $\left(11^{0} \mathrm{~N}\right.$ 
latitude, $77^{\circ} \mathrm{E}$ longitudes and an altitude of $426.26 \mathrm{~m}$ above mean sea level) to evaluate the percent disease incidence and defense reaction of cucurbitaceous rootstocks viz., Mithipakal (M.Charantia var. muricata), kumatikai (Citrullus colocynthis), African horned cucumber (Cucumis metuliferous), fig leaf gourd (Cucurbita ficifolia), pumpkin (Cucurbita moschata), zucchini squash (Cucurbita pepo), bottle gourd (Lagenaria siceraria), ash gourd (Benincasa hispida), ridge gourd (Luffa acutangula) and sponge gourd (Luffa cylindrica) and bitter gourd scions (Palee $\mathrm{F}_{1}$ and $\mathrm{CO} 1$ ) against Fusarium wilt (Fusarium oxysporum). The pathogen was isolated from bitter gourd plants showing typical wilt like symptom of Fusarium wilt by using potato dextrose agar (PDA) medium. The stock culture was maintained in Potato Dextrose Agar plates and slants, further sub cultured at monthly intervals.

\section{Screening of cucurbitaceous rootstock and bitter gourd scions for resistance to Fusarium wilt}

Fusarium oxysporum multiplied on sand - maize medium (Ricker and Ricker, 1936) was incorporated into sterilized uniform pot mixture (Red soil: Sand: FYM in 2:2:1 ratio) filled in earthen pots at the $100 \mathrm{~g} /$ pot. 30 days old rootstocks and scion seedlings were planted in the pots which contain artificially inoculated fungal pathogen and under glasshouse conditions. Five replications were maintained for each rootstocks and bitter gourd scions. The measurement of disease incidence was taken at 15, 30 and 45 days of pathogen inoculation. The disease incidence was assessed using the following formula:

Percent disease incidence $=\frac{\text { Total number of plants infected }}{\text { Total number of plants observed }} \times 100$

\section{Assay for defence related enzymes through biochemical analysis}

The biochemical constituents viz., PO, PPO and PAL were estimated in cucurbitaceous rootstocks and bitter gourd scions. Recently matured physically active roots of five randomly selected plants after inoculation were taken for biochemical analysis. Root of aforementioned species were collected at $0,7,14,21,28$ and 35 days after challenge inoculation, washed in running tap water and stored in deep freezer $\left(-80^{\circ} \mathrm{C}\right)$ until used for biochemical analysis. Samples obtained from different time interval was homogenized in chilled pestle and mortar with $2 \mathrm{~mL}$ of ice cold $0.1 \mathrm{M}$ sodium phosphate buffer $\left(\mathrm{pH} 7.0\right.$, at $\left.4^{\circ} \mathrm{C}\right)$. The homogenate was centrifuged at $16000 \mathrm{rpm}$ at $4^{0} \mathrm{C}$ for 15 minutes in a refrigerated centrifuge and the supernatant was used as enzyme source.

\section{Peroxidase (PO) activity}

Peroxidase activity was assayed by using the method of Srivastava (1987). The enzyme activity was expressed as change in ODmin $\mathrm{g}^{-1}$ of protein (Hammerschmidt et al., 1982).

\section{Poly phenol oxidase (PPO) activity}

PPO activity was determined as in Mayer et al. (1965). The PPO activity was expressed as change in OD minute $\mathrm{g}^{-1}$ of protein.

\section{Phenylalanine ammonia lyase (PAL) Activity}

PAL activity was determined as the rate of conversion of Lphenylalanine to transcinnamic acid at $290 \mathrm{~nm}$ and enzyme activity was expressed as nmol transcinnamic acid minute ${ }^{-1} \mathrm{~g}$ ${ }^{1}$ tissue (Dikerson et al., 1984).

\section{Native PAGE Analysis of PO and PPO isozymes}

To study the expression pattern of different PO and PPO isozymes in wild and cultivated cucurbitaceous rootstocks and bitter gourd scions, Native polyacrylamide gel electrophoresis (Native PAGE) was carried out (Sindhu et al., 1984 and Jeyaraman et al., 1987). After staking, the gel was washed with distilled water and photographed.

\section{Statistical analysis}

The experiments were conducted with five replications for each rootstocks and bitter gourd scions. The data were analyzed using IIRISTAT version 92-1 programme developed by the Biometric Unit, International Rice Research Institute, the Philippines. Data were subjected to analysis of variance (ANOVA) using completely randomized design following Gomez and Gomez (1976). Data in percent were square root $(X+0.5)$ transformed before analysis and the values mentioned as Mean $\pm \mathrm{SE}$.

\section{Conclusion}

The study revealed that the rootstocks viz., kumatikai (C. colocynthis), African horned cucumber (C. metuliferus) and pumpkin (C. moschata) with high levels of these biochemical constituents suffered less for Fusarium wilt pathogen and these rootstocks served as the best for grafting with bitter gourd scions followed by mithipakal

( $M$. charantia var. muricata) and sponge gourd ( $L$. cylindrica). These results indicated that all these biochemical constituents are responsible for conferring resistance to Fusarium wilt pathogen.

\section{Acknowledgements}

We gratefully acknowledge the support of funding by the "ASPEE AGRICULTURAL RESEARCH AND DEVELOPMENT FOUNDATION" Malad (W) Mumbai- 400 064, for offering research scholarship.

\section{References}

Behera TK (2004) Heterosis in bitter gourd. J New Seeds. 6(2/3):217-222.

Bruce RJ, West CA (1989) Elicitation of lignin biosynthesis and isoperoxidase activity by pectic fragments in suspension cultures of cluster bean. Plant Physiol. 91:889897.

Dikerson DP, Pascholati SF, Hagerman AE, Butler LG, Nicholson RL (1984) Phenyl alanine ammonia-lyase and hydroxy cinnamate-CoA ligase in maize mesocotyls inoculated with Helminthosporium maidis (or) $H$. carbonum. Physiol Plant Path. 25: 111-123.

Gomez KA, Gomez AA (1984) Statistical Procedure for Agricultural Research. JohnWiley and Sons, New York.

Jabeen N, Ahmed N, Ghani MY, Sofi PA (2009) Role of phenolic compounds in resistance to chilli wilt. Commun Biometry Crop Sci. 4 (2): 52-61. 
Jeyaraman KS, Ramanuja MN, Vijayaraghavan PK, Vaidyanathan CS (1987) Oxidative enzyme in pearl millet. Food Chem. 24: 203.

Kohatsu DS, Zucareli V, Brambilla WP, Elizabeth O, Silva TRB, Rodrigues JD (2013) Peroxidase and polyphenol oxidase activity on the yield of grafted and ungrafted cucumber plants. African J Agric Res. 8(3): 279-28

Mayer AM, Harel E, Shaul RB (1965) Assay of catechol oxidase: A critical comparison of methods. Phytochem. 5:783-789.

Mohamed FH, Hamed KEAE, Elwan MWM, Hussien MANE (2012) Impact of grafting on watermelon growth, fruit yield and quality. Vegetable Crops Research Bulletin. 76:99-118.

Nisini PT, Colla G, Granati E, Temperini O, Crino P, Saccardo F (2002) Rootstock resistance to fusarium wilt and effect on fruit yield and quality of two muskmelon cultivars. Scientia Horti. 93, 281-288.

Prabhukarthikeyan SR (2012) Development of bioconsortia formulation of endophytic Bacillus and Beauveria for the management of Fusarium wilt and fruit borer in tomato. M.Sc. (Ag.) Thesis, Tamil Nadu Agricultural University, Coimbatore.

Ramyabharathi SA (2011). Development and standardization of aqueous formulation of Bacillus subtilis for the management of Fusarium wilt of tomato. M.Sc. (Ag.) Thesis, Tamil Nadu Agricultural University, Coimbatore.

Saravanakumar D, Harish S, Loganathan M, Vivekananthan R, Rajendran L, Raguchander T, Samiyappan R (2007) Rhizobacterial bioformulation for the effective management of Macrophomina root rot in mungbean. Archives Phytopath Plant Protec. 40 (5): 323-337.
Satkar KP, Kulthe AA, Chalke PR (2013) Preparation of bitter gourd ready to serve beverage and effet of storage temperature on its keeping quality. Bioscan. 8 (1): 115-117

Schaller A, Ryan CA (1995) Systemin-a polypeptide defense signal in plants. Bioassays. 18: 27-33.

Sherly J (2010) Studies on grafting of brinjal accessions (Solanum melongena L.) with wild solanum rootstocks. Ph.D (Hort.) Thesis, Tamil Nadu Agricultural University, Coimbatore.

Sindhu JS, Ravi S, Minocha JL (1984) Peroxidases isozyme patterns in primary trisomics of pearl millet. Thero Appl Genet. 68: 179-182.

Singh, Singh RP (1989) Pathogenesis and Host Specificity in Plant Diseases. Elsevier Science, Oxford, UK.

Srivastava, SK (1987) Peroxidase and polyphenol oxidase in Brassica junceaplants infected with Macrophomina phaseolina (Tassi.) Goid and their implication in disease resistance. J Phytopath. 120:249-254.

Tamilselvi NA, Pugalendhi L (2015) Agronomic evaluation of bitter gourd grafts for yield and quality. Bioscan.10 (3) 1331-1334.

Tamilselvi NA (2014) Grafting studies in bitter gourd. Ph.D (Hort.) Thesis, Tamil Nadu Agricultural University, Coimbatore

Van LLC, Callow JA (1983) Transcription and translation in the diseased plant pathol. P.385-414 